FACTA UNIVERSITATIS

Series: Mechanical Engineering Vol. 18, N ${ }^{\circ} 1,2020$, pp. 43 - 55

https://doi.org/10.22190/FUME190609001M

Original scientific paper

\title{
EXPLORING STRUCTURAL DESIGN OF THE FRANCIS HYDRO-TURBINE BLADES USING COMPOSITE MATERIALS
}

\author{
Iakovos Mastrogiannakis, George-Christopher Vosniakos
}

National Technical University of Athens, School of Mechanical Engineering, Section of Manufacturing Technology, Greece

\begin{abstract}
Composite materials are increasingly exploited in industry especially replacing metallic structures due to their strength/weight ratio. Amongst the notable applications, for which composite materials have not challenged metals yet are hydroturbines, which are overwhelmingly made of steel or copper alloys. Replacing blade material by laminate composites can reduce weight and inertia, as well as achieve smaller cross-sectional thicknesses, better fatigue strength, damping, and resistance to cavitation. Manufacturing techniques are mature enough to respond to the challenge, provided that the laminate composite blades are properly designed. In the current work, the design of the Francis carbon blades was studied by employing finite element analysis. The blades were designed sub-optimally with various stratification patterns and different failure and maximum displacement limitations following a systematic methodology for gradual addition of laminate layers or patches. The methodology is still of a trial and error nature driven by the designer but guesses in the individual steps are much more informed due to model analysis and optimization tools available.
\end{abstract}

Key Words: Composites, Francis Turbine Blade, Design, Finite Element Analysis, Structural Optimization

\section{INTRODUCTION}

Traditionally, hydro turbine runners are made of stainless steel [1]. Small runners are also made of manganese brass due to its high strength and abrasion/wear resistance with the addition of $\mathrm{Fe}, \mathrm{Sn}$ and $\mathrm{Mn}$ as alloy elements or small percentage of $\mathrm{As}$ or $\mathrm{Sb}$ for anti-corrosion properties. The blades are often made separately by casting or pressing and assembling with the band and crown afterwards. Ni-Al bronze is often used to produce large blades.

Despite a very well established practice of design and manufacture of metallic blades and runners, the use of composite materials is a major challenge for the hydroturbine

Received June 09, 2019 / Accepted January 10, 2020

Corresponding author: George-Christopher Vosniakos

National Technical University of Athens, School of Mechanical Engineering, Section of Manufacturing Technology, Heroon Polytechniou 9, 15780 Zografou, Athens, Greece

E-mail: vosniak@central.ntua.gr 
industry. The low specific weight of composite materials reduces inertia; their high strength allows a smaller cross-sectional thickness and their fatigue strength is very good. Protecting them from factors such as moisture, impact, and erosion etc. is necessary and can be implemented by special coatings.

Laminate composites have been used very extensively in airfoil design, especially for wind turbines and propellers, and in hydrofoil design, especially concerning boat propellers and water turbines. In some cases, passively adaptive shapes have been achieved, i.e. foils whose shape changes in a desirable way with load.

There is rich experience in structural design of composite laminate foils on which design of hydro-turbine blades can draw, but very rarely has work been reported on hydroturbine blades as such. Work has mostly been conducted on marine turbines and propellers as well as on wind turbine blades, specially focusing on exploitation of bend-twist behavior of the blade towards achieving passive adaptivity to external load.

An advanced composite Pelton wheel was designed and fabricated, and its performance was studied for pico/micro hydro power plant application [2].

The advantages of composite materials, used in marine renewable energy structures, were demonstrated in a $2 \mathrm{~m}$ prototype of a C-power underwater turbine [3]. A decrease in thrust and an increase in power capture were achieved by the use of properly designed, passively adaptive bend-twist coupled blades in a horizontal axis tidal turbine [4]. A shape-adaptive composite propeller using bend-twist coupling characteristics of composites was developed [5]. The advantages of flexible composite marine propellers were explored in sub-cavitating and cavitating flows [6]. Optimization and experiments of composite marine propellers in changeable pitch were conducted [7]. A systematic design methodology utilized bend-twist coupling effects for performance enhancement of self-twisting composite marine propellers [8]. An efficient theoretical model was developed to obtain a first-order estimation of the static divergence speed of self-twisting composite rotors. The methodology is equally applicable to other structures, such as tidal and wind turbines [9]. A composite marine propeller for a fishing boat was designed and its performance was evaluated [10]. Theoretical and experimental exploration of bend-twist coupling and damping properties with relation to the lay-up of composite marine propellers were explored [11].

Approaches and evaluation were conducted to predict the performance of wind turbines utilizing passive smart blades [12]. A $10 \mathrm{MW}$ wind turbine blade was designed and analyzed using composite materials [13]. A design methodology of high performance composite bendtwist coupled blades for a horizontal axis tidal turbine was developed [14].

This paper reports on the design of the Francis hydroturbine blades using laminate composite materials. Based on literature review, composites may bring several advantages to hydroturbines. The main aim of the paper is to study the material replacement in the Francis hydroturbine blades with composites. This replacement has been studied for many turbines but not for the Francis type. In addition, adaptable flexible Francis blades can be designed to increase the performance of the hydroturbine.

Section 2 presents the design of a sample Francis blade, including loads obtained from CFD analysis, and presentation of candidate materials. Section 3 presents the designs of the Francis blades under failure and maximum displacement limitations. In each case studied, the respective numerical models are analyzed showing the stacking sequence, the maximum total deformation, the maximum stress, and the failure probability. 


\section{BLADE ANALYSIS}

Analysis was performed in Ansys ${ }^{\mathrm{TM}}$ software.

\subsection{Fluid flow analysis}

The blade under consideration was hydrodynamically designed at the Laboratory of Hydraulic Turbomachines the National Technical University of Athens (NTUA) as part of the small Francis hydroturbine runner with basic dimensions as follows: diameter 413 $\mathrm{mm}$, height $100 \mathrm{~mm}$, and maximum blade thickness $4 \mathrm{~mm}$. Fig. 1 illustrates the Francis runner and its components, i.e. the blades, the band, and the crown.

Fluid flow analysis using the Fluent ${ }^{\mathrm{TM}}$ solver of the entire hydro turbine runner was carried out under the following flow conditions: rotational velocity $\mathrm{w}=-157 \mathrm{rad} / \mathrm{sec}$, radial component $\mathrm{v}_{\mathrm{r}}=-6.3 \mathrm{~m} / \mathrm{sec}$ and local component $\mathrm{v}_{\mathrm{u}}=-32.9 \mathrm{~m} / \mathrm{sec}$, corresponding to a flow rate of $\mathrm{Q}=0.022743 \mathrm{~m}^{3} / \mathrm{sec}$. Fig. 2 shows the distributed pressure on the upper and lower surface of an isolated blade

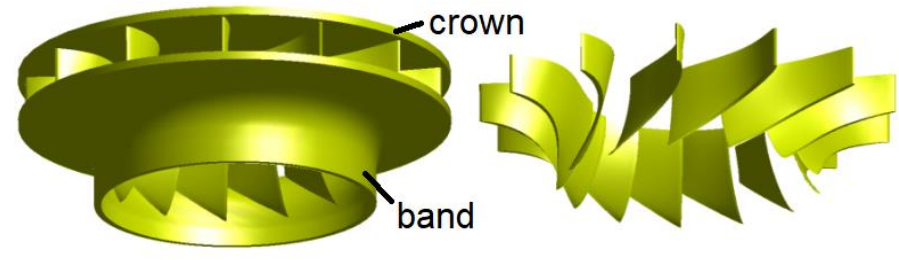

Fig. 1 Francis runner (left) and its blades (right)

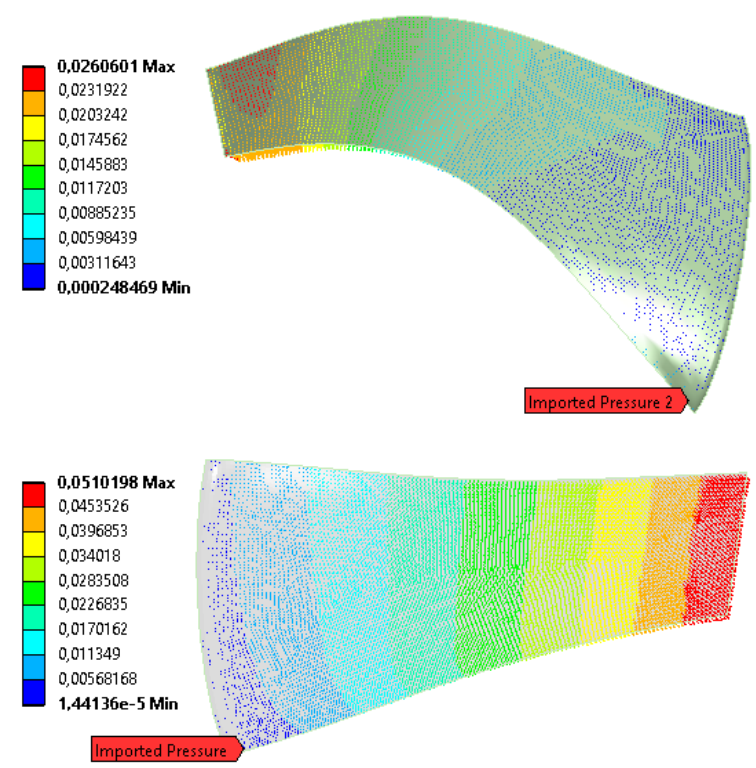

Fig. 2 Distributed fluid pressure (in hbar) on the blade (a) upper surface (b) lower surface 


\subsection{Materials}

Two carbon fiber pre-impregnated epoxy resin systems were used, implementing woven fibers and unidirectional (UD) fibers, respectively (see Table 1). Their density is $1.42 \cdot 10^{-3}$ and $1.49 \cdot 10^{-3} \mathrm{gr} / \mathrm{mm}^{3}$ respectively.

Table $1230 \mathrm{~GB}^{\mathrm{TM}}$ Epoxy Carbon pre-preg material properties

\begin{tabular}{|c|c|c|c|c|c|c|c|c|}
\hline Elasticity & Woven & UD & Stress & Woven & UD & Strain & Woven & UD \\
\hline \multicolumn{3}{|c|}{ Young's Modulus (MPa) } & \multicolumn{3}{|c|}{ Tensile strength (MPa) } & \multicolumn{3}{|c|}{ Tensile strain } \\
\hline $\mathrm{X}$ & 61340 & $1.21 \mathrm{E}+05$ & $\mathrm{X}$ & 805 & 2231 & $\mathrm{X}$ & 0.012 & 0.017 \\
\hline Y & 61340 & 8600 & Y & 805 & 29 & $\mathrm{Y}$ & 0.012 & 0.003 \\
\hline $\mathrm{Z}$ & 6900 & 8600 & $\mathrm{Z}$ & 50 & 29 & $\mathrm{Z}$ & 0.012 & 0.003 \\
\hline \multicolumn{3}{|c|}{ Poisson's Ratio } & \multicolumn{3}{|c|}{ Compressive strength (MPa) } & \multicolumn{3}{|c|}{ Compressive strain } \\
\hline $\mathrm{XY}$ & 0.04 & 0.27 & $\mathrm{X}$ & -509 & -1082 & $\mathrm{X}$ & -0.010 & -0.011 \\
\hline $\mathrm{YZ}$ & 0.30 & 0.40 & Y & -509 & -100 & $\mathrm{Y}$ & -0.010 & -0.019 \\
\hline $\mathrm{XZ}$ & 0.30 & 0.27 & $\mathrm{Z}$ & -170 & -100 & Z & -0.010 & -0.019 \\
\hline \multicolumn{3}{|c|}{ Shear Modulus (MPa) } & \multicolumn{3}{|c|}{ Shear strength (MPa) } & \multicolumn{3}{|c|}{ Shear strain } \\
\hline $\mathrm{XY}$ & 19500 & 4700 & XY & 125 & 60 & $\mathrm{XY}$ & 0.019 & 0.012 \\
\hline $\mathrm{YZ}$ & 2700 & 3100 & $\mathrm{YZ}$ & 65 & 32 & $\mathrm{YZ}$ & 0.014 & 0.011 \\
\hline $\mathrm{XZ}$ & 2700 & 4700 & $X Z$ & 65 & 60 & $\mathrm{XZ}$ & 0.019 & 0.012 \\
\hline
\end{tabular}

\subsection{Geometry and modeling}

A blade was isolated and its pressure surface selected. In order to create the blade model first a reference surface of zero thickness must be defined and then plies must appropriately be added, thus defining the thickness of the reference surface, hence of the blade. The blade pressure surface edge geometry at the water inlet side was approximated by a bevel shape as shown in Fig. 3. For the discretization of the blade model, an element size of $1 \mathrm{~mm}$ was used. In total, a mesh was formed of 7728 shell elements (10 linear triangular and 7718 linear quadrilateral) and 7929 nodes.

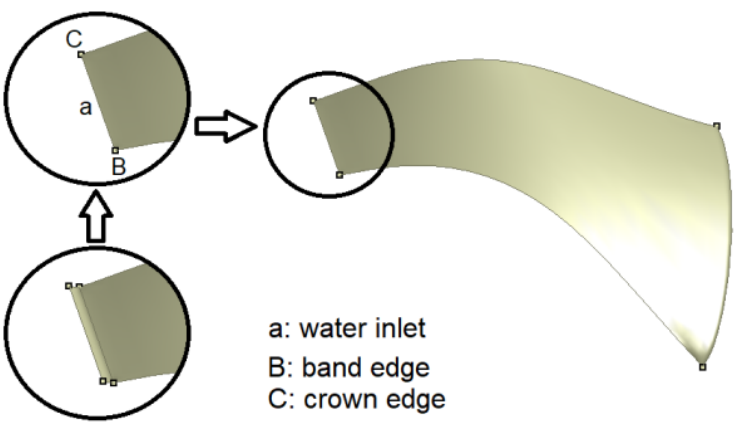

Fig. 3 Blade section at water inlet

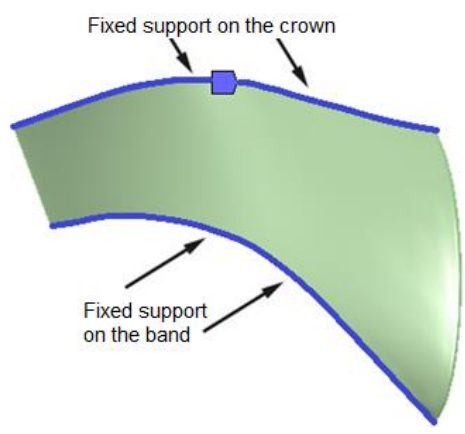

Fig. 4 Fixed support of the blade

\subsection{Boundary conditions}

Fig. 4 shows the fixed support points of the blade edges which are fully constrained. The distributed fluid pressure is added to both surfaces of the blade, see Fig. 2. The standard earth gravity and the rotational velocity of the turbine were, obviously, taken into account. 


\subsection{Failure criteria}

Inverse Reserve Factor (IRF) refers to the inverse margin to failure as a failure probability measure. Load divided by IRF yields failure load, i.e. IRF $>1$ means failure. In ANSYS $^{\mathrm{TM}}$ IRF default threshold is 0.25 , for which the failure probability is acceptably low. Failure criteria for composite blades refer to laminate plies (e.g. Max Strain, Max Stress, Tsai-Wu, Tsai-Hill, Hoffman, Hashin, Puck, LaRC and Cuntze). The failure probability caused by the fluid pressure in each ply is calculated based on each criterion because each criterion can cause maximum IRF for differing stacking sequence.

\subsection{Design methodology}

ANSYS optimization option through Response Surface Methodology (RSM) was tried, see Fig. 5. This proved useful in analyses with single layer as well as with reinforcement layers with few variables, but not in the general case, in which the design methodology illustrated in Fig. 6 was followed.

Note that in the Francis blade design, because of loads applied and the curved shape, it was observed that the woven fabrics outperform Unidirectional (UD) fabrics. In particular, it appeared that the designs with woven fabrics present better results across the studied range of orientations compared to the UD. The latter exhibited comparable results to the woven fabrics only at the optimum point. Consequently, the design with woven fabrics was preferred.

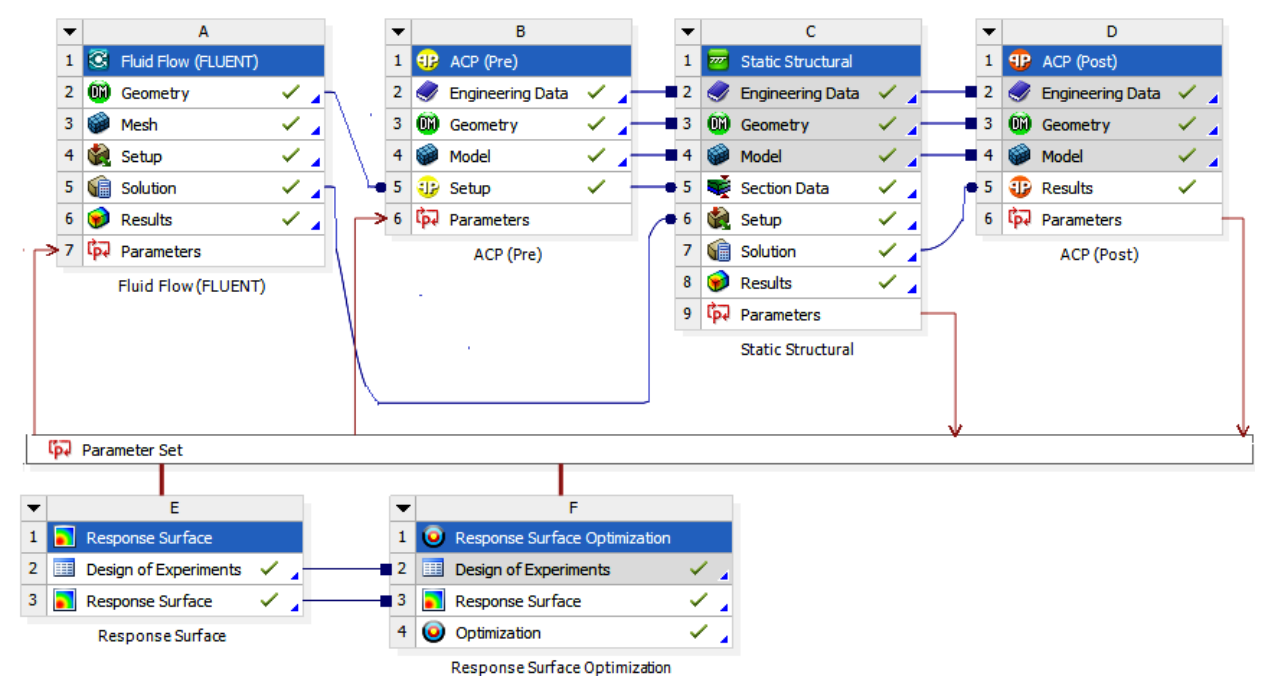

Fig. 5 RSM project schematic attempted 
The main stages are analyzed below.

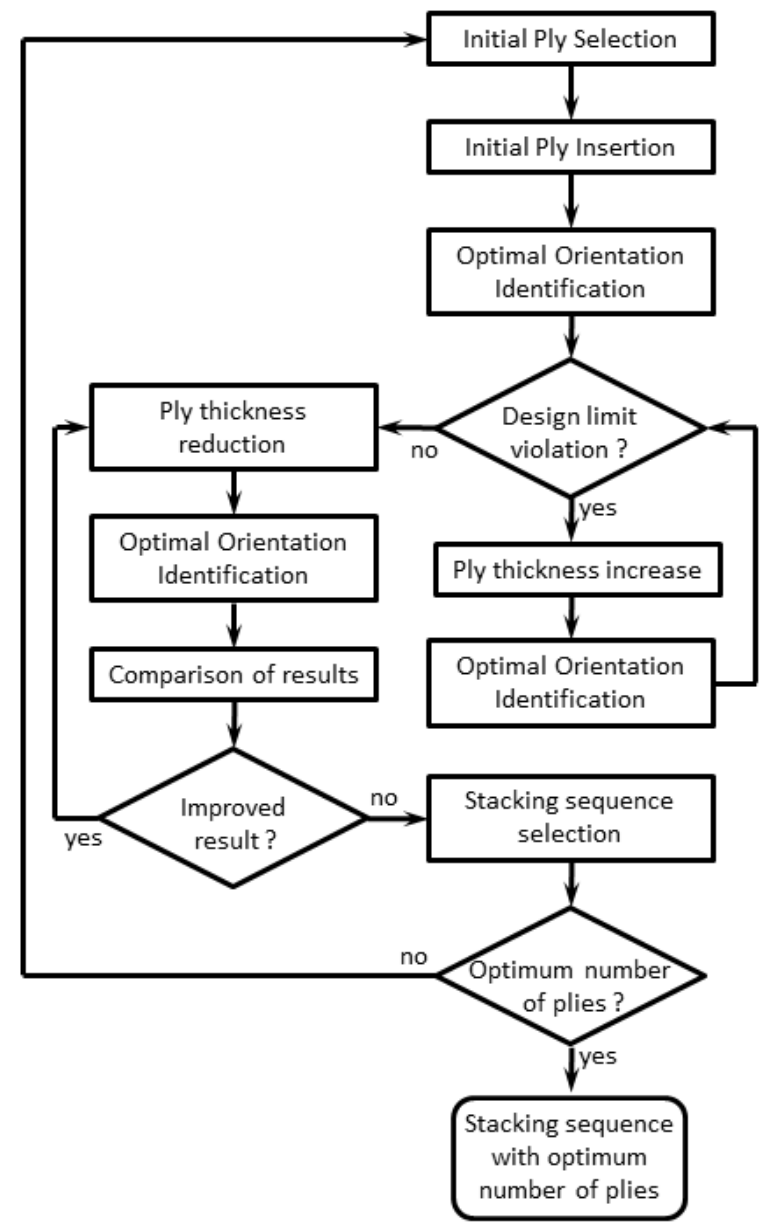

Fig. 6 Design Methodology flowchart

At the initial ply selection stage the number and orientation of plies are selected according to experience.

At the initial ply insertion stage the plies are first placed at random orientations, as follows: (a) In the case of a single layer, this is placed so that the strength design limit is reached; (b) In the case of a single layer with reinforcement patches, the thickness of the single layer is reduced to the next commercially available and at the point or points where the design limit is violated, reinforcement layers are added to reach the strength design limit; (c) In the case of a multi-layer laminate, where the strength design limit is violated, reinforcement layers are added.

At the stage of assessment and identification of optimal ply orientations, for each ply separately and all plies collectively, all possible orientations are investigated so that the plies are positioned optimally in relation to the design limit. Initially, four alternatives (e.g. $0^{\circ}, \pm 45^{\circ}$ 
and $90^{\circ}$ ) are generally considered; then, the point where the best results are observed is closely investigated. If the initially selected orientation is completely wrong, four opposing orientations are proposed to identify the optimal orientation in a short amount of time. However, in the case of the plies with a similar application area and thickness, a similar optimal orientation is observed. Thus, identifying the optimal orientation of one ply can lead to the identification of the optimal orientation of the rest if that orientation is taken as the initial one.

At the stage of ply thickness increase, thickness is increased to the next value that is commercially available: (a) In the case of a single layer with reinforcement patches, the thickness of plies is increased, the plies at the design limit violation being given priority. At the same time, minor relocation of patches may be examined, priority being given to a possible reduction in their surface area. A comparison is made between the alternative results and the best is selected. (b) In the case of a multi-layer laminate, the thickness of plies is increased and minor relocation of the reinforcement layers is examined. Furthermore, possible reduction of the size of the patches, which initially cover the entire surface of the blade, is investigated. As previously, a comparison is made between the alternative results and the best one is selected.

At the ply thickness reduction stage, the thickness of plies is reduced to the next value that is commercially available, following the flow of actions of the previous stage.

Then, the stage of comparison between the result and the previous result follows and when the best result is reached, an assessment is made to identify the optimal number of plies, this being the final result.

\section{RESULTS AND DISCUSSION}

Using the aforesaid design methodology, different analyses were performed in three different cases presented next.

\subsection{Large allowable displacement}

For this case, two models were developed. In the first model, the blade was designed with a single layer of woven fabric, as thin as possible $(0.65 \mathrm{~mm})$ see Fig. 7 (a) for the points with increased failure probability. In the second model, the blade was designed with a single layer of reduced thickness and a reinforcement patch, see Fig. 7 (b).

For both models, the blades were optimally designed using woven fabrics within the threshold of failure criteria. In the first model, the maximum total deformation is observed in the middle of the water inlet increasing at the center of the blade. The maximum stress is observed at both edges of the water inlet. Increased failure probability exists at the water inlet and in the middle of the edge that is bonded to the band.

In the second model, the maximum total deformation is observed at the center of the blade, slightly increasing in the middle of the water inlet. The maximum stress is observed at both edges of the water inlet slightly increasing at the center of the blade. An increased failure probability exists on most of the blade's surface. This shows that the blade is designed at its limits and that there is no excess material. Table 2 shows the input and output parameters for both optimized blades. 


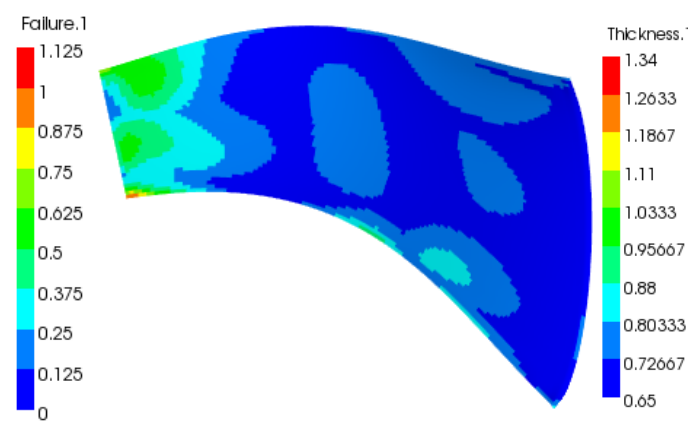

a)

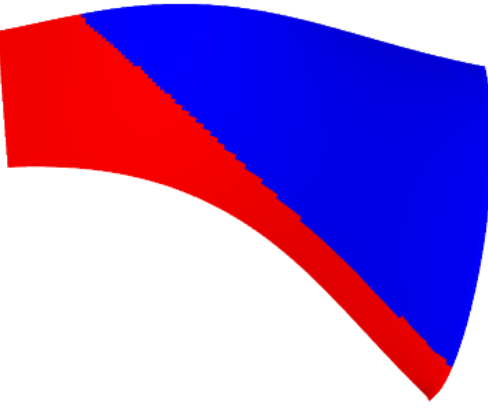

b)

Fig. 7 (a) Points with increased failure probability in a $0.65 \mathrm{~mm}$ thick single layer (b) the position of the reinforcement layer in red

Table 2 Input and output parameters for both optimized blades

\begin{tabular}{|c|c|c|c|}
\hline Model & & 1 & 2 \\
\hline Fabric & & Woven & Woven \\
\hline \multirow{2}{*}{ Single layer } & Ply thickness [mm] & 1.25 & 0.65 \\
\hline & Ply orientation $\left[{ }^{\circ}\right]$ & 0.7 & 7.1 \\
\hline \multirow{2}{*}{ Reinforcement layer From I along BE } & Ply thickness [mm] & - & 0.69 \\
\hline & Ply orientation $\left[{ }^{\circ}\right]$ & - & 79.2 \\
\hline \multirow{2}{*}{ Total deformation max $[\mathrm{mm}]$} & Value & 0.150 & 0.319 \\
\hline & Position & MI & MB \\
\hline \multirow{2}{*}{ Equiv. stress max [MPa] } & Value & 136.25 & 126.68 \\
\hline & Position & 2EI & 2EI \\
\hline \multirow{2}{*}{ IRF max } & Value & 0.249 & 0.249 \\
\hline & Position & $\mathrm{I}, \mathrm{MBE}$ & $\mathrm{B}$ \\
\hline
\end{tabular}

(I: inlet, MI: middle of inlet, B: entire blade, MB: midpoint of entire blade, BE: band edge, MBE: middle of band edge, 2EI: both edges of inlet)

\subsection{Medium allowable displacement}

For this analysis, five models were constructed to design the blade with a maximum acceptable displacement of $50 \mu \mathrm{m}$ within the threshold of failure criteria. Fabrics of thickness $0.5 \mathrm{~mm}, 1 \mathrm{~mm}, 1.5 \mathrm{~mm}$ and $2 \mathrm{~mm}$ were used. A displacement constraint serves the purpose of faithful shape retention of the blade for hydrodynamic purposes.

In the first and second model, the blades were designed with a single layer using woven and UD fabric, respectively, results being shown in Fig. 8.

In the third, fourth and fifth models, the blades were designed with a single layer and reinforcement patches, using woven fabrics based on the first model. In particular, in the third model the blade was designed with a single layer of reduced thickness $(1.5 \mathrm{~mm})$ and one reinforcement patch, see Fig. 9 (a) and (b).

In the fourth model, two smaller patches are used, see Fig. 9(c).

In the fifth model the thickness of the single layer was reduced to $1 \mathrm{~mm}$, Fig. 10 (a) illustrating the points of increased displacement and Fig. 10 (b) depicting the position of the reinforcement patches in the fifth model. 


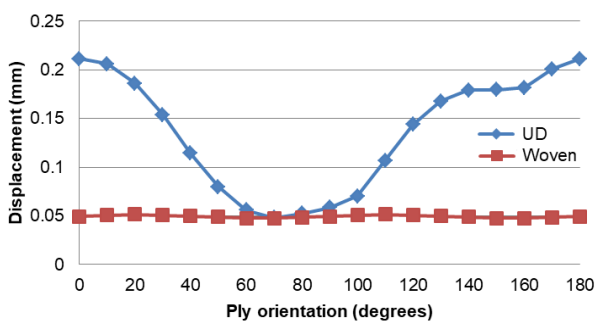

a)

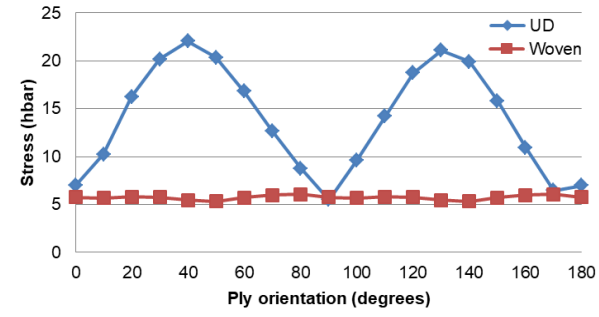

b)

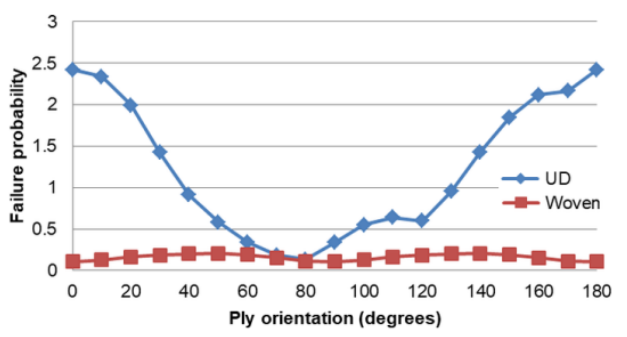

c)

Fig. 8 First and second model comparison (a) displacement (b) stress (c) failure risk

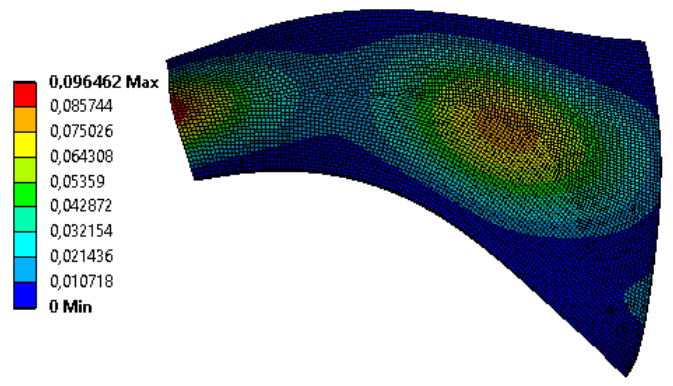

a)

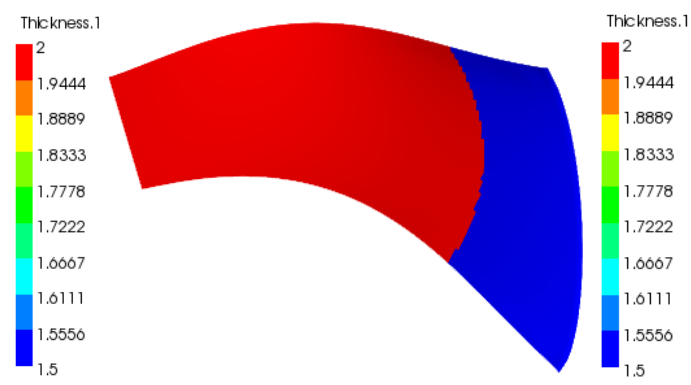

b)

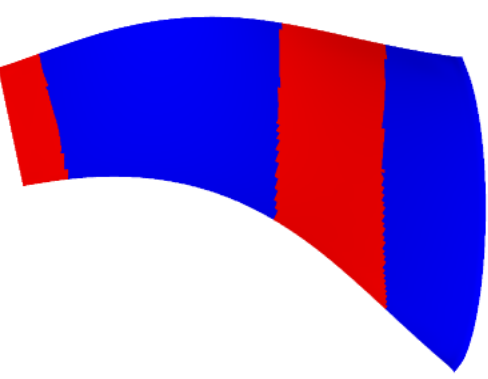

c)

Fig. 9 (a) Displacement distribution in a $1.5 \mathrm{~mm}$ thick single ply (b) reinforcement layers for third model (c) reinforcement layers for fourth model 


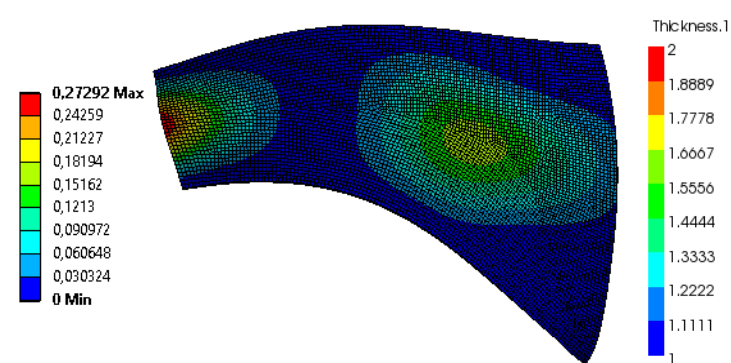

a)

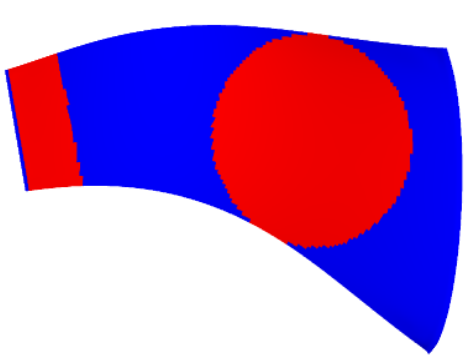

b)

Fig. 10 (a) Points with increased displacement in a $1 \mathrm{~mm}$ thick single layer (b) the reinforcement layers for the fifth model in red

In the first model, the maximum total deformation is observed in the middle of the water inlet and at the center of the blade. The maximum stress is observed at both edges of the water inlet.

In the second model, the maximum total deformation is observed at the center of the blade and increased in the middle of the water inlet. The maximum stress is observed at the edge of the water inlet bonded to the band.

In the third and fourth models, the maximum total deformation is observed in the middle of the water inlet and at the center of the blade. The maximum stress is observed at the edge of the water inlet bonded to the band and increases at the edge of the water inlet bonded to the crown.

In the fifth model, the maximum total deformation extends along the midpoint of almost the entire blade. The maximum stress is observed at the edge of the water inlet bonded to the band and increased at the edge of the water inlet bonded to the crown. All models have a very low failure probability and thus, corresponding positions are not reported. Table 3 shows the input and output parameters for all designed blades.

Table 3 Input and output parameters for medium allowable displacement

\begin{tabular}{|c|c|c|c|c|c|c|c|}
\hline \multicolumn{3}{|l|}{ Model } & 1 & 2 & 3 & 4 & 5 \\
\hline \multicolumn{3}{|l|}{ Fabric } & Woven & UD & Woven & Woven & Woven \\
\hline \multirow{2}{*}{ Single layer } & \multirow{2}{*}{ B } & PT[mm] & 2 & 2 & 1.5 & 1.5 & 1 \\
\hline & & $\mathrm{PO}\left[^{\circ}\right]$ & 70 & 70 & 65 & 70 & 70 \\
\hline \multirow{6}{*}{$\begin{array}{l}\text { Reinforcement } \\
\text { layer }\end{array}$} & \multirow{2}{*}{$\mathrm{I} \rightarrow \mathrm{CB}$} & $\mathrm{PT}[\mathrm{mm}]$ & - & - & 0.5 & - & - \\
\hline & & $\mathrm{PO}\left[{ }^{\circ}\right]$ & - & - & 20 & - & - \\
\hline & \multirow{2}{*}{ I } & PT $[\mathrm{mm}]$ & - & - & - & 0.5 & 1 \\
\hline & & $\mathrm{PO}\left[^{\circ}\right]$ & - & - & - & 30 & 0 \\
\hline & \multirow{2}{*}{$\mathrm{CB}$} & $\mathrm{PT}[\mathrm{mm}]$ & - & - & - & 0.5 & 1 \\
\hline & & $\mathrm{PO}\left[{ }^{\circ}\right]$ & - & - & - & 60 & 40 \\
\hline \multirow{2}{*}{\multicolumn{2}{|c|}{ max Deformation [mm] }} & Value & .047 & .048 & .049 & .049 & .048 \\
\hline & & Posit & MI,CB & $\mathrm{CB}$ & MI,CB & MI,CB & $\mathrm{CB}$ \\
\hline \multirow{2}{*}{\multicolumn{2}{|c|}{ max Equiv Stress [MPa] }} & Value & 59.8 & 126.0 & 55.0 & 68.0 & 76.0 \\
\hline & & Posit & $2 \mathrm{EI}$ & BEI & BEI & BEI & BEI \\
\hline \multicolumn{2}{|l|}{$\max$ IRF } & Value & 0.153 & 0.185 & 0.17 & 0.196 & 0.18 \\
\hline
\end{tabular}

(PT: ply thickness, PO: ply orientation, MI: middle of inlet, B: entire blade, $\mathrm{CB}$ : centre of blade, I: inlet, BEI: band edge of inlet, 2EI: both edges of inlet) 


\subsection{Low allowable displacement considering manufacturing cost}

A model was constructed to design the blade with a maximum acceptable displacement of $5 \mu \mathrm{m}$ within the threshold of failure criteria. Only fabrics with thickness of $0.5 \mathrm{~mm}$ were considered.

In addition, the blade has been designed for minimum manufacturing cost. A simplified cost model was used, involving material and labor for $\mathrm{n}$ plies, as follows:

$$
\text { Cost }=\sum_{i=1}^{n}\left(A C * A_{i}\right)+\sum_{i=1}^{n} L C *\left(\frac{P_{i}}{100}+\frac{A_{i}}{2500}+\frac{P_{i}}{200}\right)
$$

Fabric costs $\mathrm{AC}=30.86 € / \mathrm{m}^{2}$. The labor cost (LC) refers to the time that it takes for the technician to mark and cut the profiles on the fabric sheet and to stack each profile on the mold. After consultation with practitioners, marking and cutting time was calculated by dividing fabric ply perimeter $\mathrm{P}_{\mathrm{i}}$ (in $\mathrm{mm}$ ) by 100 while stacking time was obtained by dividing fabric area $\mathrm{A}_{\mathrm{i}}$ (in $\mathrm{mm}^{2}$ ) by 2500 and adding it to perimeter $\mathrm{P}_{\mathrm{i}}$ (in $\mathrm{mm}$ ) divided by 200. This is performed for $n$ plies. Finally, labor cost was assumed at $L C=12 €$ per hour. Tooling cost was not taken into account. Considering that labor costs depended heavily on perimeter $\mathrm{P}_{\mathrm{i}}$ of each ply, it was favorable to combine smaller plies in the same layer, which were slightly abstracted from each other, into larger single plies. Total cost was calculated at $22.96 €$ of which $20.44 €$ is attributed to labor.

Thus, the blade was designed with multiple plies using woven fabrics. In particular, it consists of 15 layers $0.5 \mathrm{~mm}$ thick, of which 3 layers extend over the entire surface of the blade (shown in blue color in Fig.11), 7 layer patches cover most of the surface of the blade, 2 patches are positioned at the water inlet (shown in yellow color in Fig. 11), and 3 patches are positioned at the center of the blade (shown in red color in Fig.11, at the middle of the blade and towards the water outlet).

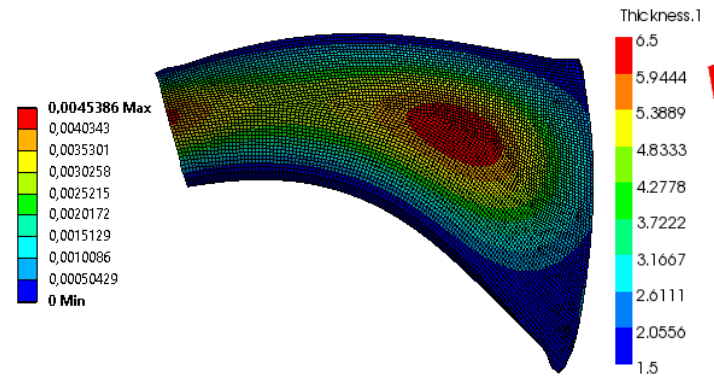

a)

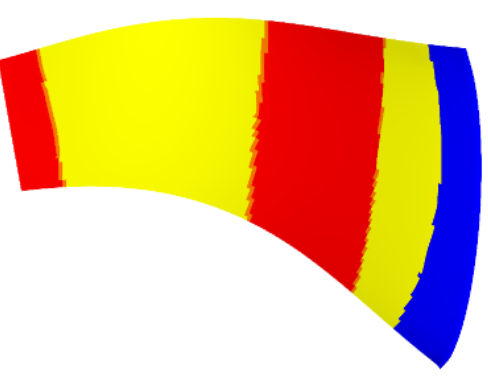

b)

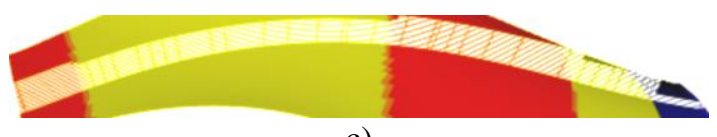

c)

Fig. 11 (a) Points with increased displacement in a laminate of max thickness $6.5 \mathrm{~mm}$ (b) position of the layers (c) stacking sequence

Fig. 11 (a) illustrates the points with increased displacement in a $6.5 \mathrm{~mm}$ thick laminate. Fig. 11(b) illustrates the position of the layers, and Fig. 11(c) presents the stacking sequence on the blade. 
The maximum total deformation extends along the midpoint of almost the entire blade. The maximum stress is observed at both edges of the water inlet. Table 4 shows the input and output parameters for the designed blade.

Table 4 Input and output parameters for the blade

\begin{tabular}{|c|c|c|c|}
\hline Fabric & & & Woven \\
\hline \multirow{8}{*}{ Layer } & \multirow{2}{*}{ EB } & PT [mm] & 0.5 \\
\hline & & $\mathrm{PO}\left[{ }^{\circ}\right]$ & {$\left[70_{3}\right]$} \\
\hline & \multirow{2}{*}{ MSB } & PT [mm] & 0.5 \\
\hline & & $\mathrm{PO}\left[{ }^{\circ}\right]$ & {$\left[60 / 65_{2} / 60_{2} / 65 / 70\right]$} \\
\hline & \multirow{2}{*}{ I } & PT [mm] & 0.5 \\
\hline & & $\mathrm{PO}\left[{ }^{\circ}\right]$ & {$[50 / 10]$} \\
\hline & \multirow{2}{*}{$\mathrm{CB}$} & PT [mm] & 0.5 \\
\hline & & $\mathrm{PO}\left[{ }^{\circ}\right]$ & {$[70 / 65 / 5]$} \\
\hline \multirow{2}{*}{\multicolumn{2}{|c|}{ max Displacement [mm] }} & Value & 0.0049 \\
\hline & & Position & MEB \\
\hline \multirow{2}{*}{\multicolumn{2}{|c|}{ max Equiv. stress [MPa] }} & Value & 7.57 \\
\hline & & Position & 2EI \\
\hline \multicolumn{2}{|c|}{ max IRF } & Value & 0.025 \\
\hline
\end{tabular}

(PT: ply thickness, PO: ply orientation, 2EI: both edges of inlet, I: water inlet, CB: centre of blade, EB: entire blade, MSB: most of blade surface, MEB: midpoint of entire blade)

\section{CONCLUDING REMARKS AND FURTHER WORK}

In the present study, sub-optimal Francis carbon fiber turbine blades were designed. The blades were as thin as possible with reduced weight and high strength.

A design methodology for laminate hydrofoil optimization was defined. Based on this methodology, the design of blades with a single layer as well as multiple layers and reinforcement patches was studied under constraints of failure and maximum displacement.

It has been observed that the change in thickness affects the results more than the change of orientation when woven fabrics are used. Comparison of a woven with a UD fabric showed that the woven fabric reach better results than UD across the range of orientations, which achieve comparable results only at the optimum orientations.

The blade design and optimization methodology was similar either with a failure limitation or a maximum displacement limitation. Whenever the thickness of plies was reduced or their orientation changed beyond the optimum point, the values of all three output parameters, i.e. failure probability, equivalent stress, and the maximum displacement increased. At different ply thickness there was a different optimal point of orientation.

Furthermore, the position selection and the reinforcement layers area were critical for the reduction of the thickness of the single layer and the three output parameters. The design and optimization process was terminated when a further reduction in plies thickness or decrease of their area and any change of their orientation led to inferior results.

The findings were similar across all analyses. In particular, the maximum displacement was observed in the middle of the water inlet and at the center of the blade, while the maximum stress was observed at the edges of the water inlet. 
Ultimately, a laminate blade of minimal cost, with woven fabrics $0.5 \mathrm{~mm}$ thick and stricter maximum allowable displacement was designed, and its manufacturing cost was analyzed. The design and optimization methodology was similar to the previous analyses, as were the effects of the maximum displacement and the maximum stress. It was observed that the main cost is attributed to labor, as opposed to material. Thus, it was preferred to increase blade volume in order to reduce total cost. Moreover, it was generally observed that blade cost is reduced by using the minimum required number of plies, which however has a negative impact on the accuracy and optimality of the results.

As short term future research, fatigue strength should be explored, following an established method [15]. In the long run, an adaptable flexible Francis blade with partially fixed support, variable thickness and optimized ply orientation will be explored following the same methodology that was presented in this work.

\section{REFERENCES}

1. Steele, R.D., 2007, Hydraulic turbines, In: E.A. Avallone, T. Baumeister AMS, (Eds.), Marks' Standard Handbook for Mechanical Engineers. 11th ed. McGraw-Hill, pp. 9154-9166.

2. Khabirul Islam, A.K.M., Bhuyan, S., Chowdhury, F., 2013, Advanced composite pelton wheel design and study its performance for pico/micro hydro power plant application, Int J Eng Innov Technol., 2(11), pp. 126-132.

3. Mohan, M., 2008, The advantages of composite material in marine renewable energy structures, Marine Renewable Energy Conference (RINA), London, pp. 41-57.

4. Nicholls-Lee, R.F., Turnock, SR, Boyd, SW., 2013, Application of bend-twist coupled blades for horizontal axis tidal turbines, Renew Energy, 50, pp. 541-550.

5. Herath, M.T., Gangadhara Prusty, B., Yeoh, G.H., Chowdhury, M., John, N.S., 2013, Development of a shape-adaptive composite propeller using bend-twist coupling characteristics of composites, Third International Symposium on Marine Propulsors, Launceston, Tasmania, pp.128-135.

6. Young, Y.L., 2008, Fluid-structure interaction analysis of flexible composite marine propellers, J Fluids Struct., 24(6), pp.799-818.

7. Lin, C.-C., Lee, Y.-J., Hung, C.-S., 2009, Optimization and experiment of composite marine propellers, Compos Struct., 89(2), pp. 206-215.

8. Liu, Z., Young, Y.L., 2009, Utilization of bend-twist coupling for performance enhancement of composite marine propellers, J Fluids Struct., 25(6), pp. 1102-1116.

9. Liu, Z., Young, Y.L., 2010, Static divergence of self-twisting composite rotors, J Fluids Struct., 26(5), pp. 841-847.

10. Hara, Y., Yamatogi, T., Murayama, H., Uzawa, K., Kageyama, K., 2011, Performance evaluation of composite marine propeller for a fishing boat by fluid-structure interaction analysis, 18th International Conference on Composite Materials, Jeju Island, Korea, p. 6.

11. Ahmed, A., 2012, Theoretical and experimental methods on bend-twist coupling and damping properties with the relationship to lay-up of the composite propeller marine: A review, Int J Eng Sci Technol., 4(6), pp. 2907-2917.

12. Maheri, A., Isikveren, A., 2010, Performance prediction of wind turbines utilising passive smart blades: approaches and evaluation, Wind Energy, 2(3), pp. 255-265.

13. Cox, K., Echtermeyer, A., 2012, Structural design and analysis of a $10 \mathrm{MW}$ wind turbine blade, Energy Procedia, 24, pp.194-201.

14. Nicholls-Lee, R., Boyd, S., Turnock, S., 2009, Development of high performance composite bend-twist coupled blades for a horizontal axis tidal turbine, 17th International Conference on Composite Materials, UK, p. 10.

15. Ciavarella, M., Carbone, G., Vinogradov, V., 2018, A critical assessment of Kassapoglou's statistical model for composites fatigue, Facta Universitatis-Series Mechanical Engineering, 16(2), pp. 115 - 126. 